\title{
EFECTOS DE CAMPOS MAGNÉTICOS EN EL METABOLISMO Y CRECIMIENTO DE LACTOBOCILLUS YE. COLI
}

\author{
Iván Ramírez Jiménez, Yat Sen Wong, Sandra León López, \\ Juan Ramos Gorbeña, Fernando Torres y Víctor Zapata Cánepa
}

\section{RESUMEN}

El desarrollo del proyecto en la primera etapa involucró el uso de laboratorios, de microbiología y el laboratorio piloto de investigación, debido a la necesidad de compartir equipos para diferentes procesos que requería el cultivo de Lactobacillus plantarum. En la segunda etapa y en esta última etapa solo se trabajó en el laboratorio piloto. Se han desarrollado los trabajos de aislamiento y cultivo microbiológico, y de preparación de los sistemas de generación de campo magnético alterno de hasta $53 \mathrm{kHz}$. Se ha logrado obtener la influencia del campo magnético variable en el crecimiento del Lactobacillus, observando que las muestras sometidas a campo en tiempos cortos y mediana frecuencia han producido un aumento de colonias aproximadamente en un $70 \%$ más, comparado con las muestras control.

Palabras ClaVE: Campos magnéticos alternos, crecimiento, metabolismo, Lactobacillus.

\section{EFFECTS OF MAGNETIC FIELDS AND GROWTH METABOLISM OF LACTOBOCILLUS AND E. COLI}

\begin{abstract}
The development of the project in the first stage involves the use of laboratories, microbiology and pilot research laboratory, because of the need to share equipment for different processes requiring the cultivation of Lactobacillus plantarum. In the second stage and at this late stage only worked on the pilot laboratory. They have developed insulation work, and microbiological preparation and systems generating alternating magnetic field of up to $53 \mathrm{kHz}$ culture. It has been possible to obtain the influence of variable magnetic field on the growth of Lactobacillus, noting that the samples subjected to field in short and medium frequency times have produced an increase of approximately colonies in $70 \%$ more, compared to the control samples.
\end{abstract}

KEYWORDS: Alternating magnetic fields, growth, metabolism, Lactobacillus. 


\section{Introducción}

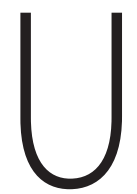

no de los sectores que presenta mayor auge en el Perú, es la industria de lácteos con una tasa anual de crecimiento de $9 \%$. Dentro de sus derivados son bienes altamente cotizados el queso y el yogurt, que en nuestro país presentan un pujante sector artesanal e industrial en desarrollo. Esta producción se basa en la utilización de bacterias lácticas como Lactobacillus acidophilus y $\mathrm{S}$. thermofillus, que se valen de su capacidad de desdoblar la lactosa y de fermentar azucares.

El estudio de los factores biofísicos involucrados en el proceso biotecnológico de la fermentación y sus consecuencias son de completo interés, estos son; la temperatura, $\mathrm{pH}$, concentración de nutrientes y oxigeno. La velocidad de fermentación del proceso está en una relación directa con el nivel de división y concentración celular, siendo esta característica la principal en los procesos de producción, ya que determinan el nivel de la calidad del producto.

Una de las fuerzas que afecta a todo organismo sobre la tierra es el campo magnético, que no puede ser percibido de manera clara, pero tiene gran influencia en los sistemas vivos, debido a la capacidad de alterar el flujo de iones a través de la membrana celular, de re direccionar las biomoléculas y hasta entrar en resonancia con las moléculas orgánicas. Estos efectos son observables metabólicamente a nivel de un organismo procariota en su división celular y sobre todo en los canales de iones, estructuras proteicas asociadas a la membrana.

Para incrementar el conocimiento y aplicabilidad en el campo de la, biotecnología, se ha trabajado en la investigación de los posibles efectos de los campos magnéticos de baja intensidad en el crecimiento y metabolismo de Lactobacllus acidophilus, y Plantarum utilizando exposiciones variables de tiempos, con intensidades del orden de miliGauss y de frecuencias en los órdenes de los Khz.

\section{Objetivos}

\section{General:}

- Determinar la influencia del campo magnético de intensidad variable y de baja frecuencia en el crecimiento y metabolismo de Lactobacillus y E. coli.

\section{Específicos:}

- Determinar el rango de intensidad óptima de campo magnético sobre el crecimiento y desarrollo de Lactobacillus.

- Evaluación del metabolismo de Lactobacillus bajo la influencia de campo magnético en comparación con los producidos en condiciones normales. 


\section{Hipótesis}

La exposición de un campo magnético variable de baja intensidad fomentara a una mayor división celular y no afectara al metabolismo de Lactobacillus con respecto a los expuestos a condiciones normales.

\section{Método}

\section{Materiales insumos y equipos usados}

Material biológico:

Cepas ATCC Lactobacillus

Medios de cultivos:

Caldo MRS Rogosa

Caldo BHI

Agar MRS Rogosa

\section{Materiales de vidrio}

Tubo de ensayo sin tapa $5.5 \mathrm{ml}$

Pipeteador pump de $25 \mathrm{ml}$

Biker $250 \mathrm{ml}$

Embudo mediano

Probeta $50 \mathrm{ml}$

Tubos tapa rosca pyrex $13 \times 100$

\section{Equipos}

Autoclave

estufa

termómetro

Mechero

Cámara de NeuBauer

Espectrofotómetro

Microscopio con adaptación de cámara fotográfica

Generador de funciones $10 \mathrm{khz}-1 \mathrm{MHz}$

Osciloscopio de $20 \mathrm{MHz}$

Medidor de campo magnético de alta frecuencia

Bobinas generadoras de campo magnético de $10-60 \mathrm{kHz}$

Voltímetro

Inductametro. 


\section{Adquisición de insumos y materiales}

En los meses de junio y noviembre del 2013 Se adquirieron los materiales medios e insumos necesarios, la relación y costos está en el (anexo 10) cuya rendición de cuentas se hizo el 7 de noviembre del 2013 a las oficinas del la dirección de economía, con copia al vicerrectorado y decanato. Cuyo monto ascendió, al total del recorte efectuado en el presupuesto inicial del proyecto que fue solo de S/. 3962.00 soles.

\section{Adquisición de equipos de laboratorio}

Se adquirió un modesto equipo medidor de campo magnético de alta frecuencia en los EE.UU (anexo 3) una autoclave, estufa, frigider y materiales de vidrio con peculio propio de los investigadores.

\section{Implementación de equipos en el laboratorio}

En el lugar de trabajo, que es un cubículo del laboratorio 211 de la FCB se implemento de equipos, de la siguiente manera:

- se consiguió un osciloscopio de $20 \mathrm{MHZ}$ en calidad de préstamo de uno de los investigadores.

- se consiguió un generador de funciones en calidad de préstamo de la facultad de ingeniería de la Escuela de electrónica cedida por el Ing. Víctor Zapata C.

- Para los trabajos de pruebas de influencia del campo magnético en los medos de cultivo se adquirieron carretes de alambre de cobre esmaltado con peculio propio, de uno de los investigadores ya que el presupuesto no alcanzo.

- Se instalaron una estufa un frigider con peculio propio de uno de los colaboradores.

- En la segunda etapa se adecuo el cubículo con sistemas de controles contra la contaminación de bacterias con peculio propio de todos los involucrados en la investigación

- Se adquirió una autoclave con peculio propio del responsable de la investigación.

\section{Diseños y construcciones experimentales.}

- En la primera etapa paralelamente a los trabajos de desarrollo bacteriano, se fueron diseñando las bobinas que serían las necesarias para la investigación. Para lo cual se elaboró un pequeño software (anexo 6) y se construyeron bobinas circulares magnéticas, (anexo 4) con la colaboración del Sr Fernando Torres asistente del laboratorio de Física de la Facultad de Ingeniería, para hacer las pruebas de influencia de campo a distintitas frecuencias. 
- Se ha logrado a diseñar y construir varias bobinas que funciona muy bien entre las frecuencias de $10-53 \mathrm{KHz}$, tenemos problemas con el funcionamiento de las bobinas a más de $60 \mathrm{KHz}$, el campo presenta mucha inestabilidad.

- Se calibraron los campos magnéticos alternos producidos dentro de las bobinas mediante el método de extrapolación de funciones exponenciales (anexo 2 ) ya que el equipo del que disponemos tiene un rango max. Limitado de medida de la inducción magnética. (anexo 3)

- En el proceso de calibración de una de las bobinas, explorando el funcionamiento en bajas frecuencias se cometió un error y se quemo el generador de funciones. Este incidente retrasó el trabajo, ya que tuvimos dificultades para la reparación, y los costos no están aceptados en el presupuesto del proyecto.

\section{Desarrollo de los trabajos en el aspecto biológico}

Inicialmente se ha procedido en el área de microbiología haciendo lo siguiente:

- La Implementación de los procedimiento de esterilización del material de vidrio y otros.

- La Implementación del procedimiento de preparación de los medios de cultivo deshidratados.

- La Implementación del procedimiento de viabilizacion de las cepas de cultivo.

- La Estandarización del procedimiento para la evaluación y el recuento bacteriano tanto de Lactobacillus acidophilus y plantarum.

Para los cuales se programaron reuniones de trabajo interdiario (lunes - miércoles - viernes) y dos reuniones que involucraron la permanencia en el laboratorio 211 de un lapso de tiempo de 24 horas para poder así determinar la curva de crecimiento de las bacterias empleadas en el presente estudio.

Se utilizaron medios de cultivos específicos para su desarrollo como el agar Mc Conkey y el agar MRS, ambos medios de cultivos permitieron el crecimiento de los microorganismos sembrados en diferentes tiempos durante 24 horas.

En esta primera etapa de estandarización, se han cometido errores y en consecuencia se ha tenido que implementar medidas correctivas durante el procedimiento del recuento bacteriano.

De los dos ensayos que se programaron se obtuvieron resultados no precisos durante el recuento bacteriano, esto debido a un inadecuado procedimiento de homogenización, para lo cual se tomaron las medidas correctivas.

\section{Nuevo procesamiento de las muestras}

En la segunda etapa, (como medida correctiva) como paso inicial se procedió a la reactivación de la cepa ATCC Lactobacillus plantarum en Agar Tripticasa soya, por ser un medio 
de cultivo no selectivo, e incubo a $37^{\circ} \mathrm{C}$ por $24 \mathrm{~h}$. Se sembró una colonia en $5 \mathrm{ml}$ de Caldo MRS, y se dejó incubar a $37^{\circ} \mathrm{C}$ por $24 \mathrm{~h}$.

El cultivo control y el experimental de L. plantarum tuvieron las mismas condiciones nutricionales, factores externos de temperatura, humedad y el tiempo para desarrollarse hasta las 18 horas y obtener un cultivo joven. El cultivo indicado como experimental se expuso al campo magnético por un tiempo de 3 minutos. Para luego pasar a hacer las diluciones (dilución hasta -13) y la siembra de la última dilución preparada, por el método de diseminación en placas (0,1 ml de la muestra se coloca sobre la placa y se estría con un asa de Digralsky con Agar Plate Count. Después de lo cual las placas debieron mantenerse sin voltear sobre la mesa por 5 min aproximadamente, para evitar que la muestra aun fresca se pueda escurrirse a un lado de la placa, y se llevó a la incubadora a $37^{\circ} \mathrm{C}$ por $24 \mathrm{~h}$ para el desarrollo de las colonias.

Después, se procedió a realizar el recuento de colonias, (anexo 9) siendo estas blanquecinas y de aproximadamente 20 um. El número total del conteo, se multiplica por la última dilución de siembra para obtener el valor en UFC/ml.

\section{Resultados}

En la primera etapa pareció que se había logrado calcular la curva de crecimiento del lactobacillus utilizando un método alternativo, de mayor eficacia y menor costo, utilizando la cámara de Neubauer y el espectrofotómetro. Este método alternativo fue ideado debido a la falta de equipos y la dificultad del método comúnmente utilizado, que es el método de inmersión en placa. A partir de la dilución y su absorción correspondiente se logro calcular la concentración para cada dilución, y las ecuaciones de las gráficas son Abs= dilusionx $53.33+7.9$ y Abs=concentx $0.178-0.12$. Pero luego se presentaron dificultades de valoración de desarrollo de las bacterias (anexo 1).

Para la generación de los campos de inducción magnética de distinta frecuencia, se han diseñado, construido y probado cinco bobinas tipo Helmholtz de diferentes características que pueden producir campos magnéticos estables hasta $60 \mathrm{KHz}$. en el orden de los miliGauss.

En la segunda etapa se ha logrado obtener la influencia del campo magnético variable en el crecimiento del Lactobacillus, observando que las muestras sometidas a campo en tiempos cortos y mediana frecuencia en una de las bobinas ha mostrado un aumento de colonias (anexos 7 y 8) comparado con las muestras control. Esta diferencia se ha podido obtener en tres siembras, consecutivas, luego de que se consiguió contrarrestar las contaminaciones sistemáticas en el laboratorio. No se ha realizado todavía, ninguna acción con la E.Coli. 


\section{Discusión}

Considerando que no hemos podido disponer de referencias en otros trabajos exactamente en cepas de lactobacillus sometidos a campos magnéticos, pero si uno similar, pero trabajado, con otro tipo de bacterias, que también tienen las propiedades de fermentación , como es el trabajo "Efectos de los campos magnéticos sobre el crecimiento de Saccharomyces cerevísiae "desarrollado por Zapata, M y otros 6 . Que muestran la influencia de de algunas frecuencias de campos magnéticos variables del orden de los KHz en el desarrollo de Saccharomyces cerevísiae, Podemos afirmar que en la presente investigación, hemos podido encontrar que en tres pruebas consecutivas en lactobacillus plantarum, la acción de un campo magnético variable dentro de los órdenes de los 50 $\mathrm{KHz}$, perpendicular al campo magnético terrestre, con una intensidad de 100 miliGauus, las muestras expuestas a disparos de una duración de 180 segundos, dentro de una bobina especialmente diseñada con la configuración Helmholtz, han mostrada una fuerte influencia del campo de inducción magnética, generando desarrollos sorpresivos del lactobacillus, que de acuerdo a los resultados experimentales y los cálculos realizados (anexos 7 y 8) se tienen un incremento del mas del $70 \%$. Lo que significa que la velocidad de desarrollo de la fermentación, casi se ha duplicado en el mismo tiempo comparado con las muestras no expuestas al campo, a las que nosotros llamamos control.

Si estos resultados se volverían a repetir en trabajos siguientes la hipótesis quedaría completamente probada, y luego se perfilaría una siguiente investigación a nivel de aplicación en un prototipo de proyección industrial.

Es menester considerar que los resultados obtenidos, es el fruto del esfuerzo, de haber considerado y probado tres métodos para desarrollo de las colonias de bacterias, solo con el tercer método utilizando agua peptonada y con diluciones hasta - 13 se ha llegado a los resultados que se está reportando. Un terrible inconveniente que se presentó en el desarrollo de la investigación, fue la continua y seguida contaminación de las cepas sembradas, que se presentaron debido a la falta de condiciones de esterilización del ambiente en el laboratorio de clases, en el que fue desarrollado parte del trabajo. Esto condujo a la necesidad de ir implementando el lugar con mejores condiciones para evitar la contaminación, y que el costo de los resultados sean menos onerosos y más eficientes.

\section{Referencias bibliográficas}

Liboff, A William, T; Strong, D; WistaR, R Time -Varying Magnetic Fields: Effect on DN A Synthesis Science 223:818-820 (1984).

DiHeL, L; SMith - SONNEBORN J; Russell, C Effects of and extremely low frequency electromagnetic field on the cell division rate and plasma membrane of Paramecium tetraurelia. Bioeletromagnetics 6:61-71 (1985). 
J. A. MAiKO; I. COnStantinidís ; D, DillehaY; W. A Fajman Seach for influences of I. S Tesla Magentic Field on growth of Yeast ceil Bioelectromagnetics 15: 495-501 (1994).

GoldSWORTHY, A; WITHNEY, H; MORRIS, E. Biological effects of physiclly conditioned water Wat Res. vol 33, No 7, pp. 1618-1626\{1999\}.

ZHADIN Mikhail N. Review of Russian Literature on biological action of DC and Low frequency AC Magnetic fields. Bioelectromagnetics 22:27-45 (2001).

ZAPATA, M; Moreno, G; Márquez, E Efectos de los campos magnéticos sobre el crecimiento de Saccharomyces cerevísiae. Ínterciencia vol 27, num 10 Octubre (2002).

V.V. Ledniev. Biophysics. vol. 41 Bioefects of weak combined, constant and variable magnetic fields pag. (241-252) (1996). 


\section{ANEXOS}

\section{Anexo 1. Primeros intentos de recuento de bacterias}

Método para recuento de bacterias utilizando un espectrofotómetro
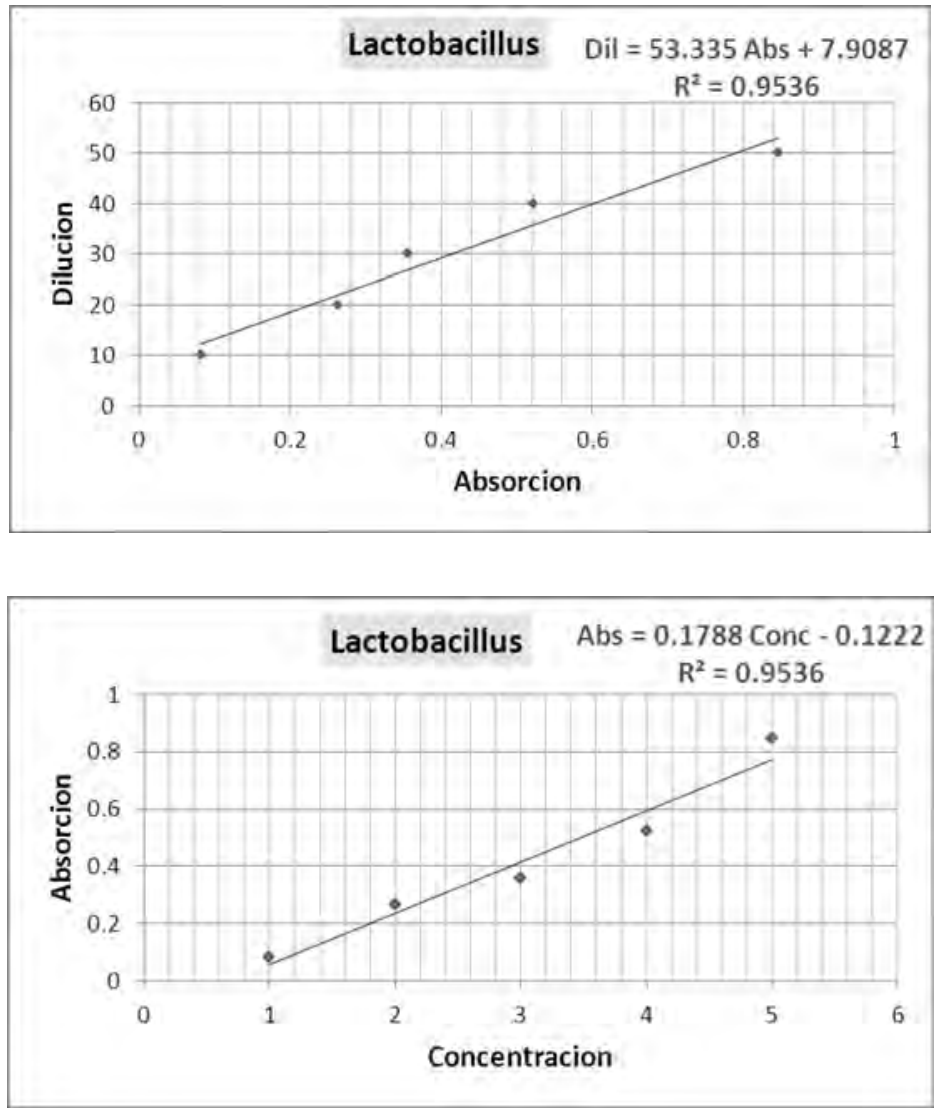

Este método no nos dio buenos resultados, suponemos por la falta de calibración del espectrofotómetro usado. 


\section{Anexo 2. Calibración de los campos magnéticos producidos por la bobinas, por el método de extrapolación de curvas}

Cálculos de valores del $\vec{B}$ por extrapolación, en la misma bobina \#1 a distintas amplitudes

196 vueltas alambre \#AWG 32, 3 capas de bobinas , $5 \mathrm{~cm}$ de diámetro Resistencia eléctrica $51.6 \mathrm{ohm}$

El campo en el interior es aproximadamente 908 mG

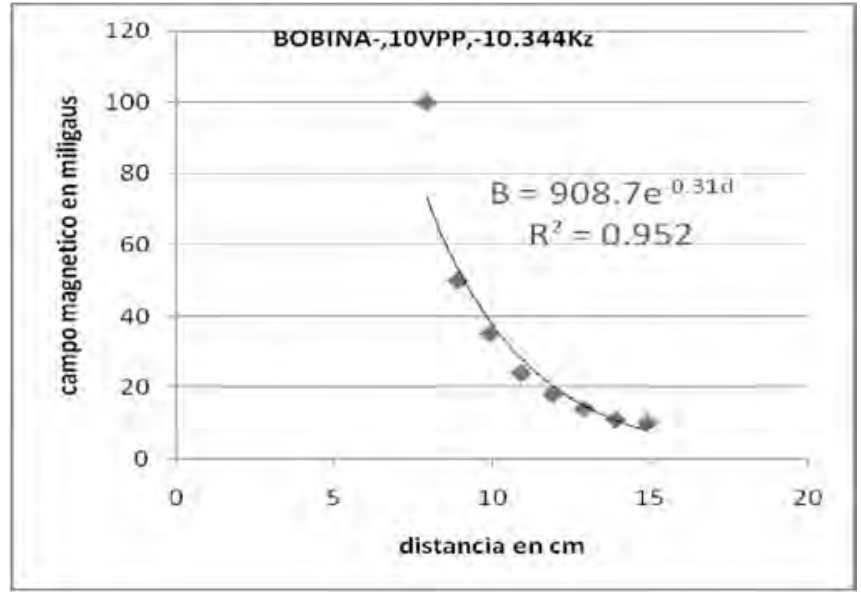

El campo en el interior es aproximadamente $2810 \mathrm{mG}$

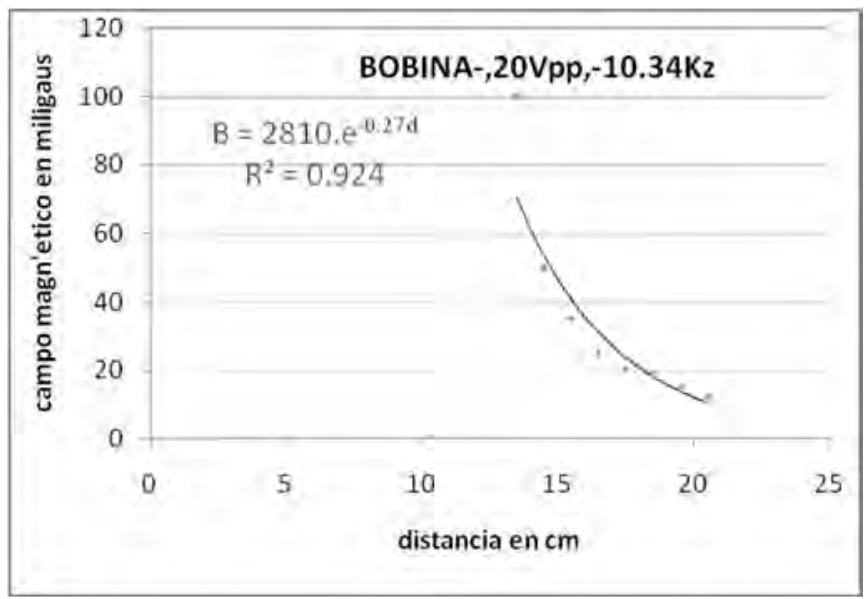


Anexo 3. Este equipo medidor simple, adquirido con peculio propio, nos ayudó en la medición de las distintas intensidades de los campos magnéticos, a los que fueron sometidas las muestras

TRIFIELD ${ }^{\text {TM METER }}$

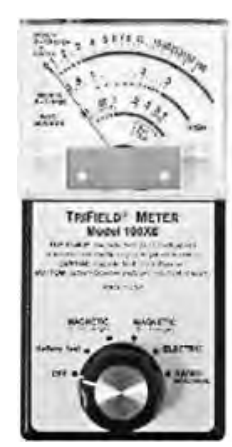

- Magnetic Field; 3 axis

- $\quad$ Electric Field; 1 axis

- Microwave

EX100 Version

Frequency: $50 \mathrm{~Hz}-100 \mathrm{kHz}$

Magnetic Field Range 1: 1-100 mG

Magnetic Field Range 2: 0.2-3 mG

Electric Field Range: 5-1000 V/m

Frequency: $50 \mathrm{MHz}-3 \mathrm{GHz}$

Microwave Range: $0.01-1 \mathrm{~mW} / \mathrm{cm}^{2}$

Display: needle gauge

Accuracy: good

Quality: better

Power: $9 \mathrm{~V}$ (included)

Other: best for electromagnetic field surveys

(Cat. \#EN150-60) ... US\$149.95 each 
Anexo 4. Todas las Bobinas diseñadas y construidas para generación de campo B máximo a distintitas frecuencias fueron probadas una por una hasta conseguir, la que más alta frecuencia nos daría, y en la que la medición de campo sea estable

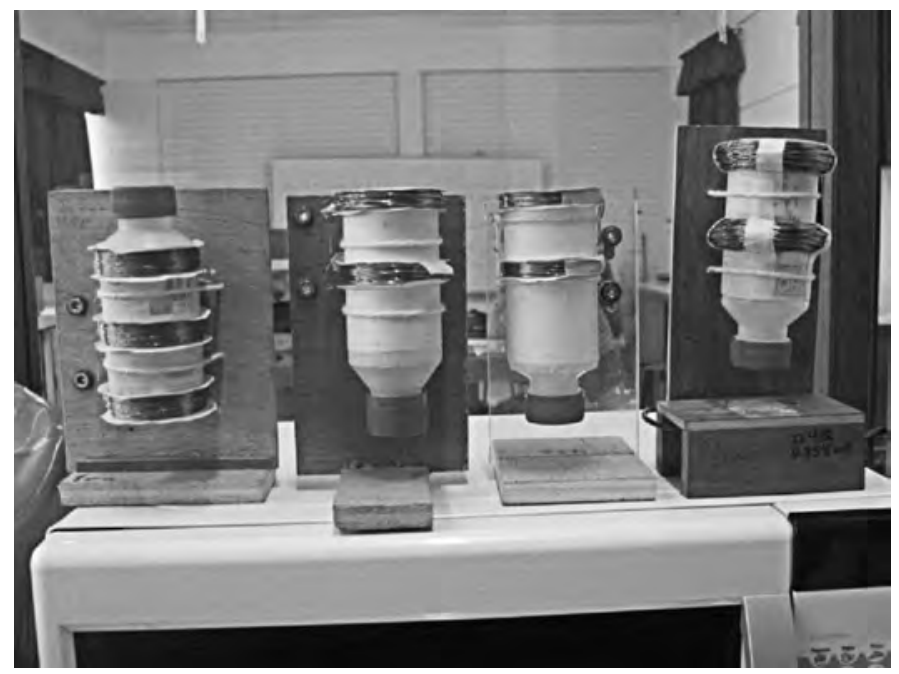

Resultados de las primeras bobinas tipo Helmholtz diseñadas y construidas en el año 2013

\begin{tabular}{ccccccccc}
\hline Bobina \# & \# awg & $\begin{array}{c}\text { \# de } \\
\text { vueltas }\end{array}$ & $\begin{array}{c}\text { \# de } \\
\text { bobinas }\end{array}$ & $\begin{array}{c}\text { diámetro } \\
\mathrm{cm}\end{array}$ & $\begin{array}{c}\text { Resistencia } \\
\text { Ohms }\end{array}$ & $\begin{array}{c}\text { Inductancia } \\
\text { en milihenrios }\end{array}$ & $\begin{array}{c}\text { Max Rango } \\
\text { de frecuencia } \\
\text { en Khz }\end{array}$ & $\begin{array}{c}\text { \# de } \\
\text { conductores }\end{array}$ \\
\hline 1 & 32 & 196 & 3 & 5.25 & 51.6 & & $1-10$ & Unifilar \\
\hline 2 & 32 & 400 & 2 & 5.25 & 32.6 & 6.05 & $10-15$ & Unifilar \\
\hline 3 & 21 & 100 & 2 & 5.25 & 1.2 & 0.415 & $10-30$ & Unifilar \\
\hline 4 & 21 & 24 & 2 & 5.25 & 0.3 & 0.101 & $10-20$ & Unifilar \\
\hline 5 & 21 & & 2 & & 0.4 & 0.354 & $20-60$ & Doble \\
\hline 6 & - & - & - & - & - & & & \\
\hline
\end{tabular}

Tenemos las bobinas ya listas para someter a las bacterias a un campo magnético variable de hasta $60 \mathrm{kHz}$.

Tenemos problemas con el diseño de bobinas a mayor frecuencia, no obstante que se han realizado los primeros intentos, todavía no hemos podido construirlas. El medidor de campo indica mucha inestabilidad a los $60000 \mathrm{~Hz}$.

El medidor de campo es muy inestable no nos permite medir la intensidad de campo. Con los métodos antes utilizados con las primeras bobinas, para determinar el valor del campo, todavía no nos es posible encontrar los valores de campo por extrapolación. 
Anexo 5. Disposición de los equipos Osciloscopio, generador y medidor de campo de inducción magnética en miliGauss

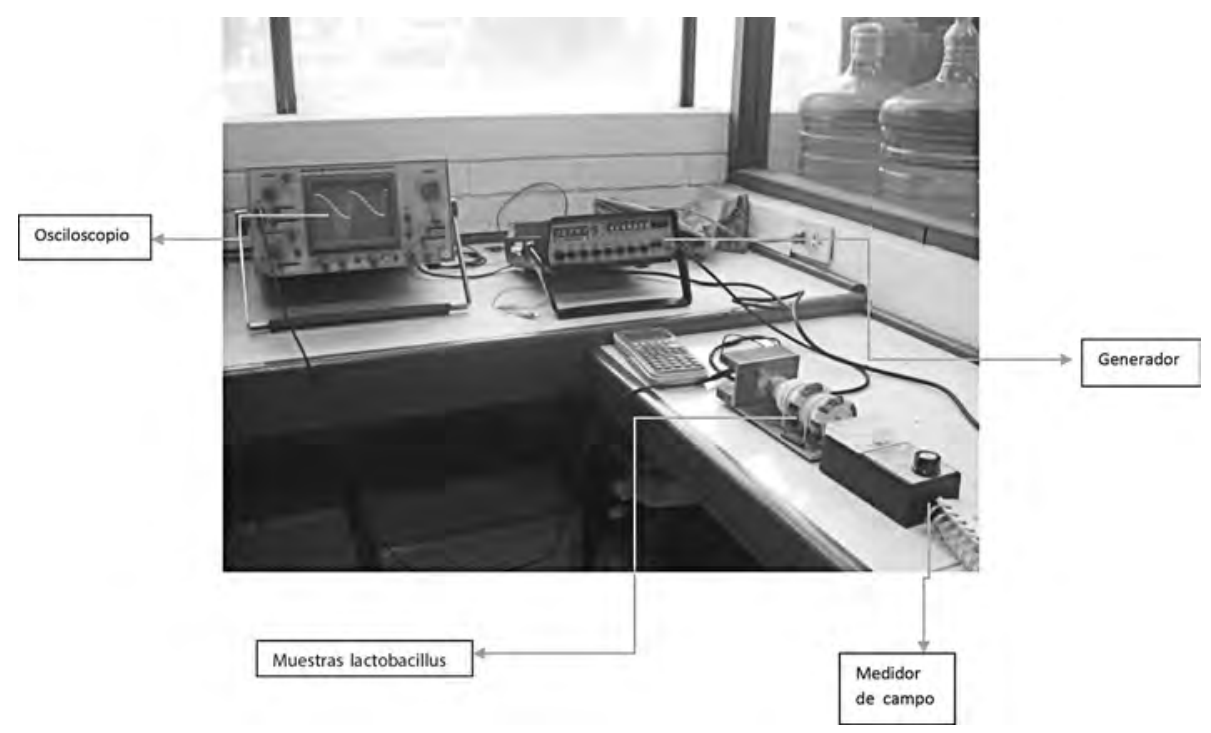

Anexo 6. Software creado para el cálculo aproximado de bobinas

\begin{tabular}{|c|c|c|c|c|c|c|c|c|c|}
\hline - habina de helmhaltz. & prof. wan ramirez & \multicolumn{2}{|c|}{ mayo 7013} & \multicolumn{6}{|c|}{$-[\bar{x}$} \\
\hline \multicolumn{2}{|c|}{ calculo del campo B en gauss } & \multicolumn{2}{|l|}{ devanados } & & Dit. & $a x$ & Eura & 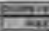 & 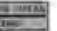 \\
\hline \multirow{6}{*}{ 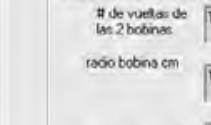 } & 1 & & & 足 & $=$ & 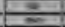 & 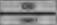 & $=1$ & $\therefore$ \\
\hline & & long del delaribre & Teds & 4 & son & कom & $\sin$ & Dom & Sen \\
\hline & & & & $\frac{10}{n}$ & $\frac{\sin }{n g}$ & 0 & क्जा & and & क्जि \\
\hline & 100 & disomethe de latiote & & $=$ & $=0$ & $=0$ & जाi & 800 & \begin{tabular}{|c|}
5108 \\
\end{tabular} \\
\hline & & 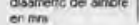 & 1 & F & $\sin$ & 13 & Fes & $\sin$ & 214 \\
\hline & & & & III & 80 & 8010 & 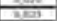 & Bins & Ding \\
\hline \multirow{3}{*}{ contente en A } & 1 & secain del cuen & Texdio & in & 80 & Doln & ans & inis & प्राश \\
\hline & & & & 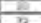 & 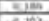 & 70015 & Song & 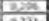 & $5 x$ \\
\hline & & retelencia del & Tent1 & 31 & \begin{tabular}{|c|c|}
$\sin$ \\
\end{tabular} & 0015 & $\infty$ & Des & 20 \\
\hline \multirow{3}{*}{ camoc B reda } & $\sqrt{\text { Tent4 }}$ & alsentre en ormi & & $\frac{50}{2}$ & $\frac{\cos s}{\sin x}$ & $\frac{9015}{804}$ & $\frac{12}{2 x}$ & 3203 & Don \\
\hline & & & & $n$ & ogas & 0000 & क्या & जs: & 20 \\
\hline & & Voldere necteiatio & $\operatorname{lex} 12$ & $w$ & on & $8.0,0$ & not & क्या & 0,0 \\
\hline \multirow{4}{*}{ nillets } & Tet5 & & & 28 & 50 & 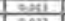 & 201 & sum & $x$ \\
\hline & jeats & & $\operatorname{Ient13}$ & $\frac{n}{21}$ & $\frac{-945}{c^{4} \sin }$ & $\frac{30 n}{80 n}$ & is & 을 & $\frac{\sin 4}{\cos 3}$ \\
\hline & & potencia miniena & Texis & $\frac{1}{2}$ & $\Delta=$ & $\cos ^{2}$ & 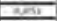 & $\cos$ & $\sin$ \\
\hline & Teat5 & envalies & & $\pi$ & $0 \times 1$ & 507 & $+\infty$ & $\mathrm{sen}$ & क्या \\
\hline \multirow{2}{*}{ gaus } & & & & $\frac{11}{20}$ & $\frac{306}{603}$ & $\frac{\operatorname{sen}}{\operatorname{son}}$ & $+\infty$ & Stan & $\frac{\sin }{\operatorname{sen} \mid}$ \\
\hline & & 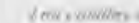 & $f_{1}=\mathrm{awh}$ & 11 & $=\sin$ & कon & - 254 & $\operatorname{sen}$ & $\mathrm{sm}$ \\
\hline \multirow{4}{*}{ magouns } & Tot? & Som wawn & & $\frac{11}{12}$ & $\frac{1,2}{6,5}$ & ogin & 5 & ing & … \\
\hline & & & & 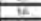 & $\frac{100}{100}$ & Dals & 80 & 100 & twat \\
\hline & & & & 13 & क्या & 8 & जिए & $15+$ & हिया \\
\hline & & & & 11 & in & क्या: & An & Tans & 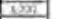 \\
\hline \multirow{5}{*}{ mascay } & & \multirow{5}{*}{\multicolumn{2}{|c|}{ ज्रिक }} & $\frac{13}{18}$ & $\frac{16}{4 x^{2}}$ & & 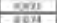 & & $\frac{|c| c \mid}{401}$ \\
\hline & & & & in & $7=$ & + & 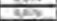 & 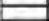 & $x=$ \\
\hline & & & & 10 & 15 & & 8 & & 20 \\
\hline & & & & 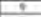 & 39 & $=$ & stai & $=$ & $7 x$ \\
\hline & & & & 1 & $\frac{1 x}{10}$ & & $\frac{\operatorname{sen}}{5}$ & & Dons \\
\hline
\end{tabular}




\section{Anexo 7. Resultados de la investigación}

1. Comparando el desarrollo de colonias control y sometidos al campo magnético de $53 \mathrm{kHz}$ a $100 \mathrm{mG}$ expuestos a $3 \mathrm{~min}$. En ellas claramente se muestran las diferencias de cantidades de colonias.

Nomenclatura

$-12 C$ - son las colonias control

-12 - son las colonias expuestas a campo magnético

29 de setiembre del 2014
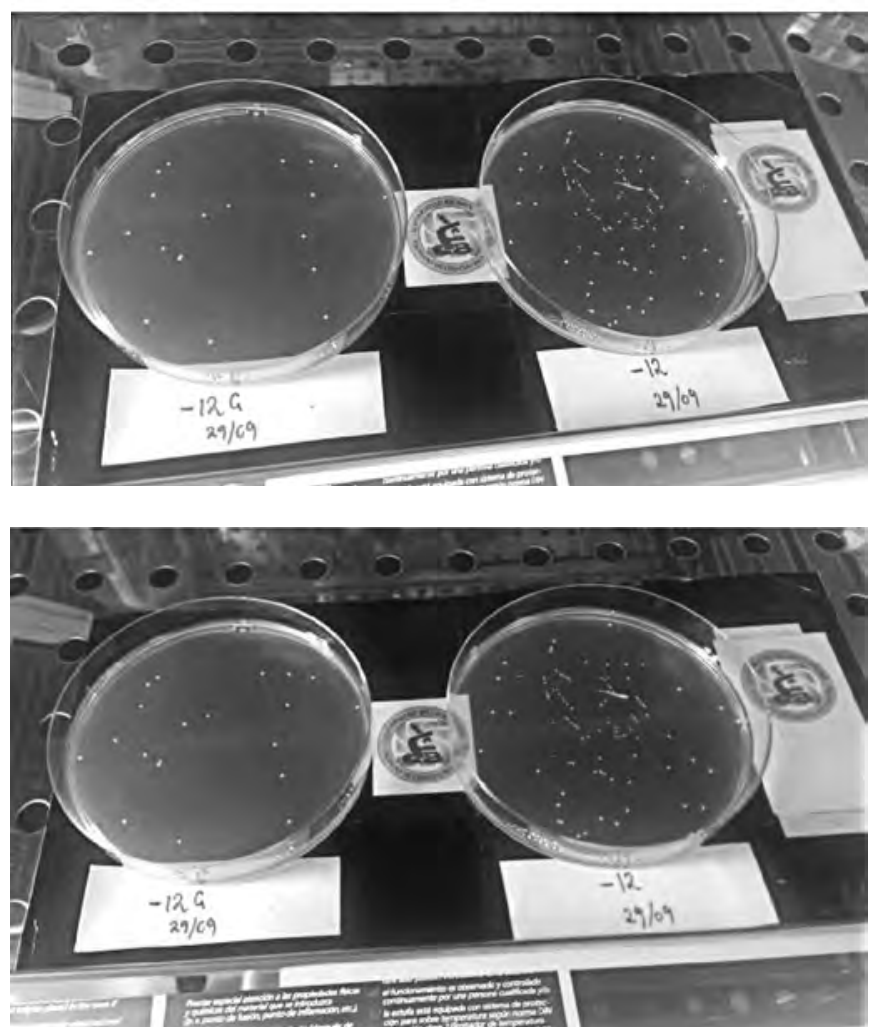
2- Comparación del desarrollo de colonias control y sometidos al campo magnético de $53 \mathrm{kHz}$ a $100 \mathrm{mG}$ expuestos a 3 min. 7 de octubre del 2014.
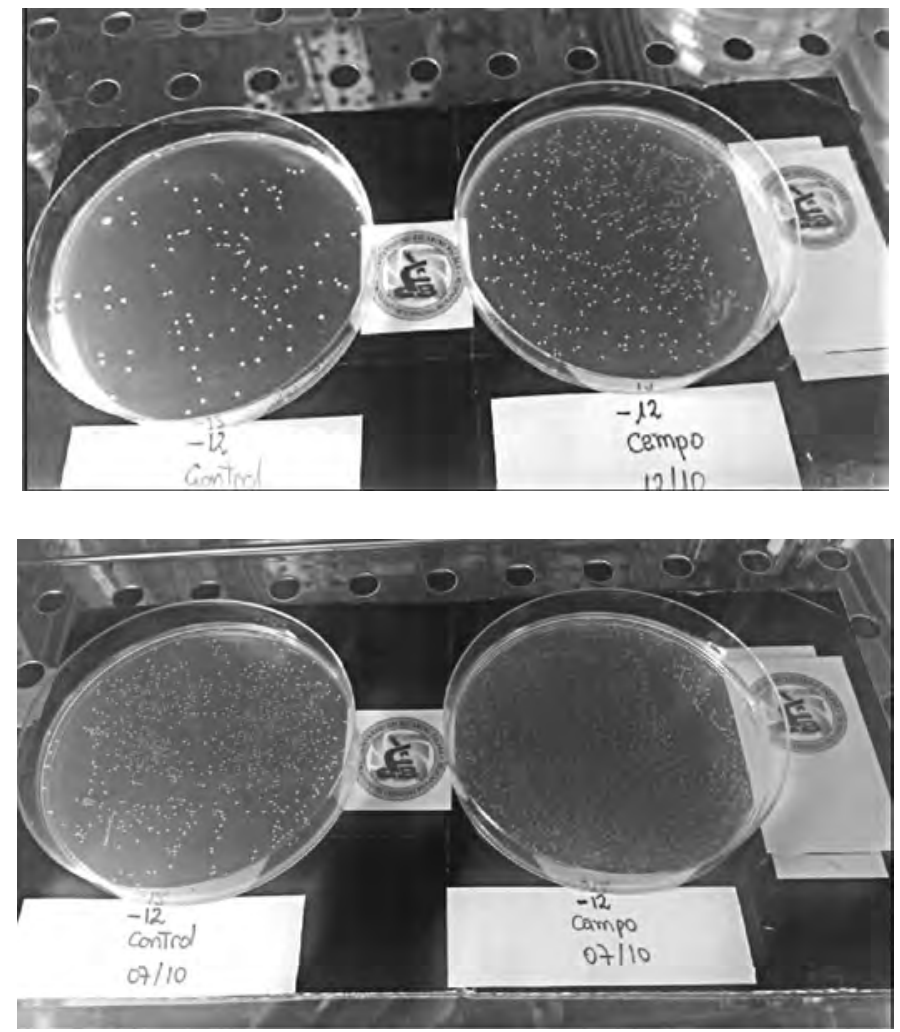

3 - Comparación del desarrollo de colonias control y sometidos al campo magnético de $53 \mathrm{kHz}$ a $100 \mathrm{mG}$ expuestos a $3 \mathrm{~min}$.

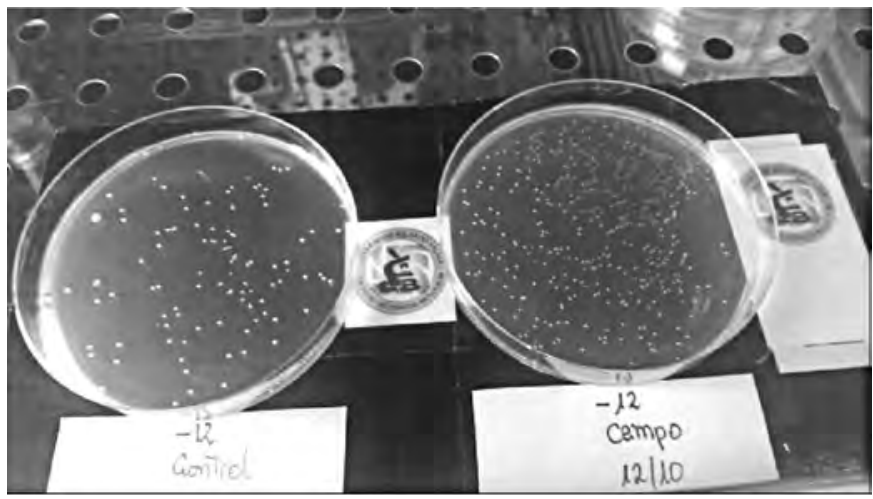




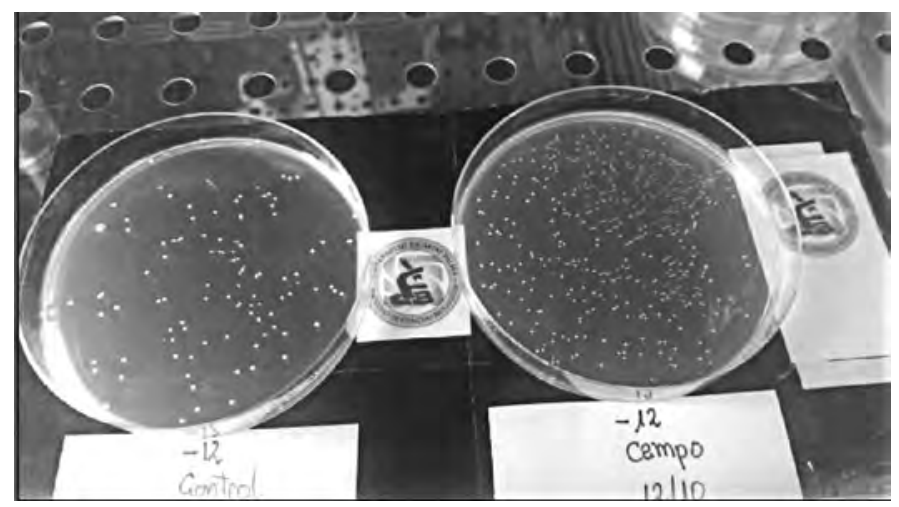

12 de octubre del 2014

\section{Anexo 8. Lectura de placas}

28 set. 2014

dilucion $\quad-12$

\begin{tabular}{|l|l|l|}
\hline \# placa & $\begin{array}{l}\text { \# de colonias } \\
\text { control }\end{array}$ & $\begin{array}{l}\text { \# colonias de } \\
\text { con campo }\end{array}$ \\
\hline a & 232 & 332 \\
\hline b & 232 & 318 \\
\hline prom & 232 & 325 \\
\hline
\end{tabular}

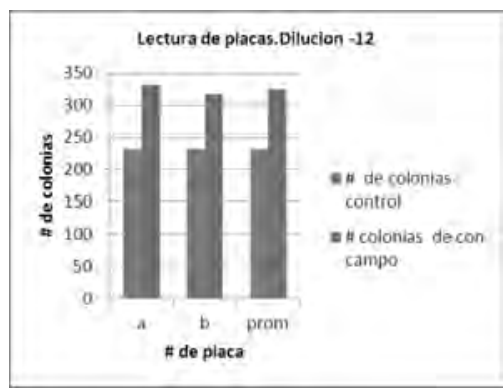

2 oct. 2014

dilucion $-12$

\begin{tabular}{|l|l|l|}
\hline \# placa & $\begin{array}{l}\text { \# de colonias } \\
\text { control }\end{array}$ & $\begin{array}{l}\text { \# colonias de } \\
\text { con campo }\end{array}$ \\
\hline a & 27 & 58 \\
\hline b & 14 & 53 \\
\hline C & 41 & 73 \\
\hline prom & 29 & 61.3 \\
\hline
\end{tabular}

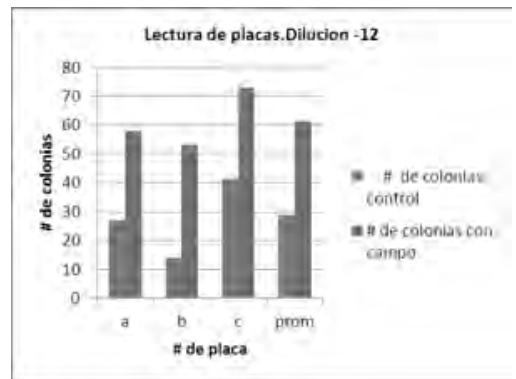

En el primer caso se muestra que las colonias sometidas a campo muestran un $40.08 \%$ de mas desarrollo, mientras que en el segundo caso, es en $111 \%$ mas. Siendo el promedio de las dos siembras de las distintas fechas $75.54 \%$. 
Anexo 9. Muestra de recuento de bacterias solo referencial sujetos a mayores investigaciones

\begin{tabular}{|c|c|c|c|c|c|c|c|c|c|c|}
\hline $\begin{array}{l}\text { Fecha de } \\
\text { análisis: }\end{array}$ & $\begin{array}{l}\text { Campo } \\
\text { mG }\end{array}$ & cultivo & $\begin{array}{l}\text { Frecuencia } \\
(\mathrm{KHz})\end{array}$ & $\begin{array}{l}\text { Tiempo de } \\
\text { exposición }\end{array}$ & Dilucior & i Recuento 1 & Recuento 2 & Recuento 3 & recuento & $\mathrm{OFC} / \mathrm{mL}$ \\
\hline $9 / 28 / 2014$ & 100 & & 49.457 & 3 & -12 & 332 & 318 & & 325 & $1.39 E+30$ \\
\hline $9 / 28 / 2014$ & 100 & & 49,457 & 3 & -12 & 232 & & & 232 & $2.43 E+28$ \\
\hline $10 / 1 / 2014$ & 100 & & 49,457 & 3 & -12 & 27 & 19 & 41 & 29 & $3.53 E+17$ \\
\hline $10 / 1 / 2014$ & 100 & & 53 & 3 & -12 & 58 & 53 & 73 & 61.33 & $2.83 E+21$ \\
\hline $10 / 16 / 2014$ & 100 & & 53 & 3 & -10 & 83 & 83 & & 83 & $1.55 E+19$ \\
\hline $10 / 16 / 2014$ & 100 & & 53 & 3 & -10 & 170 & 253 & & 211,5 & $1.79 E+23$ \\
\hline $10 / 16 / 2014$ & 100 & & 53 & 3 & -11 & 31 & 33 & & 32 & $3.60 E+16$ \\
\hline $10 / 16 / 2014$ & 100 & & 53 & 3 & -11 & 102 & 113 & & 107.5 & $2.22 \mathrm{E}+22$ \\
\hline $10 / 16 / 2014$ & 100 & & 53 & 3 & -12 & 28 & 28 & & 28 & $2.30 E+17$ \\
\hline $10 / 16 / 2014$ & 100 & & 53 & 3 & -12 & 56 & 72 & & 64 & $4.72 E+21$ \\
\hline $11 / 8 / 2014$ & 100 & & 50 & 3 & -12 & 561 & 392 & & 476.5 & $1.37 E+32$ \\
\hline $11 / 8 / 2014$ & 100 & & so & 3 & -12 & 769 & 781 & & 775 & $4.69 E+34$ \\
\hline
\end{tabular}

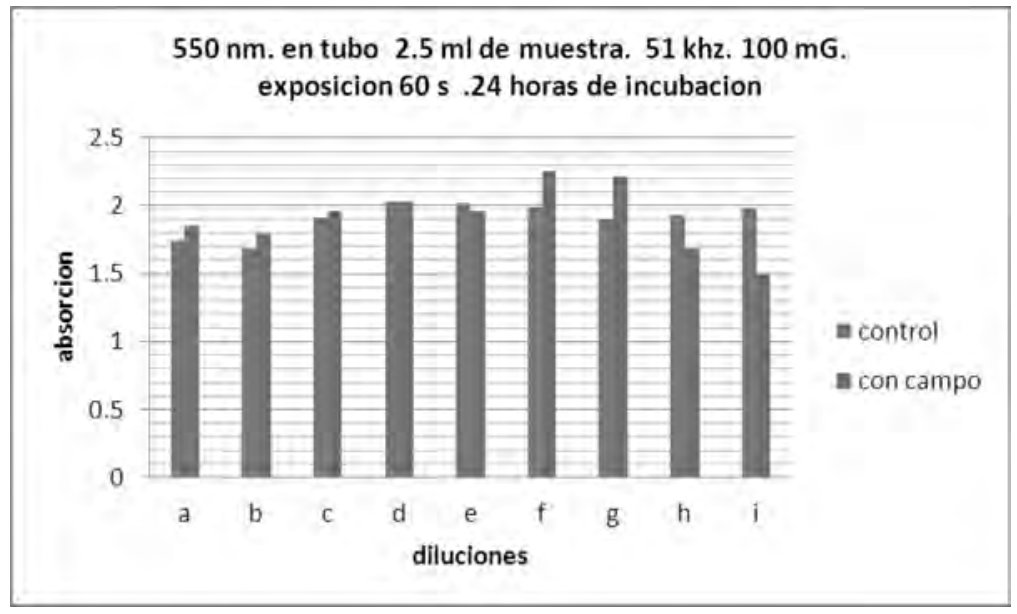

Inoculando y preparando diluciones

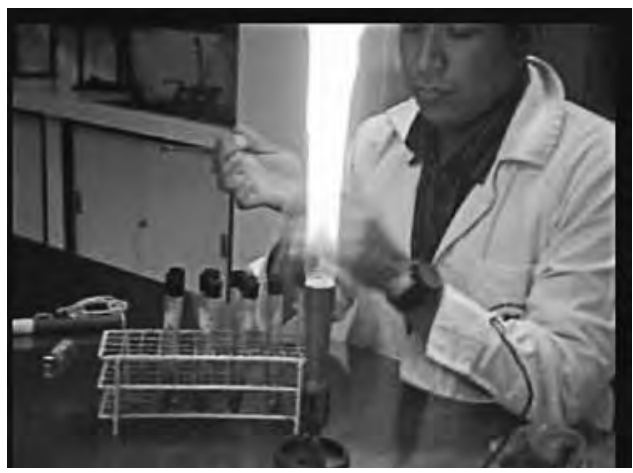


